\title{
The Normativity of Rationality
}

6048 words (including notes, excluding abstract and works cited)

\begin{abstract}
This article is an introduction to the recent debate about whether rationality is normative - that is, very roughly, about whether we should have attitudes which fit together in a coherent way. I begin by explaining an initial problem - the "detaching problem" - that arises on the assumption that we should have coherent attitudes. I then explain the prominent "wide-scope" solution to this problem, and some of the central objections to it. I end by considering the options that arise if we reject the wide-scope solution.
\end{abstract}

Philosophers have long taken the requirements of morality to face a certain kind of skeptical challenge. On the face of it, for example, there is a moral requirement to keep your promises, in circumstances where the alternative is a minor inconvenience. But according to a certain kind of skeptic, there might be no reason for you to keep your promises in such circumstances - it all depends, such a skeptic might say, on your interests, or on the ends you happen to have. Philosophers have devoted a lot of energy trying to answer skeptics of these sorts. But it has often been assumed that there are other types of requirement that are not so open to skeptical challenge. Among the most common candidates for this role are requirements to have attitudes which fit together in a coherent way - for example, requirements to believe the obvious and non-trivial consequences of your beliefs, to avoid flatly contradictory beliefs, and to intend what you take to be the necessary means to your ends. There is no serious question, many philosophers have assumed, about whether these requirements are genuine normative requirements - requirements you should, and so have reason to, comply with. ${ }^{1}$

In recent years however, many philosophers have come to think that things are not so clear - that there is indeed a serious question about whether, for example, you should intend what you take to be the necessary means to your ends, or avoid flatly contradictory beliefs. This question is often put, more generally, by asking whether, necessarily, you should, or even have any reason to, comply with rational requirements - requirements to have attitudes which fit together in a coherent way. ${ }^{2}$ In this article, I shall explain some of the arguments that have lead philosophers to take this question seriously. I shall then consider how we should respond if these arguments succeed. 


\section{The Detaching Problem}

Let's begin with what should be a simple case: the requirement to avoid flatly contradictory beliefs. It is easy to motivate the idea that there is a requirement of this sort. We need only reflect that something is going wrong if you exhibit the following pattern of beliefs:

(Inconsistency in belief) You believe that $\mathrm{p}$ and believe that not-p.

Since something is going wrong if you exhibit this pattern, it is natural to suppose that there is a norm or principle prohibiting you from doing so. We might express this by saying, somewhat stipulatively, that rationality requires you to avoid this pattern. And we might initially want to formulate this requirement, more exactly, as follows:

(Belief Consistency*) If you believe that $\mathrm{p}$, rationality requires you not to believe that not-p.

However, on reflection, it is clear that, so formulated, this requirement cannot be correct. At least this is so if we assume the normativity of rationality:

(Normativity) If rationality requires you to A, you should A.

The problem is easily illustrated. Suppose that the evidence that not-p is conclusive but that you believe that $p$ anyway, perhaps because of wishful thinking, or because you are taken in by an obvious fallacy. It follows from Belief Consistency* and Normativity that you should not believe not-p. But by hypothesis, the evidence that not-p is conclusive. So if you have any view on the matter, not-p is what you should believe. Belief Consistency* and Normativity cannot both be correct. ${ }^{3}$

Consider now the requirement to intend what you take to be the necessary means to your ends. Again, it is easy to motivate the idea that there is such a requirement. We need only reflect that something is going wrong if you exhibit the following pattern of attitudes: 
(Means-end incoherence) You intend to $\mathrm{E}$, believe that $\mathrm{M}$ is necessary for $\mathrm{E}$, but do not intend to $\mathrm{M}^{4}$

Since something is going wrong if you exhibit this pattern, it is natural to suppose that there is a norm or principle prohibiting you from doing so. However, the norm cannot be the following:

(Means-End*)

If you intend to $\mathrm{E}$, and believe that $\mathrm{M}$ is necessary for $\mathrm{E}$, rationality requires you to intend to $\mathrm{M}$.

For on the assumption of Normativity, Means-End* has absurd implications. For example, suppose that you intend to get the job, and believe that assassinating your main rival is necessary for getting the job. It follows from Means-End* and Normativity that you should intend to assassinate your rival. But of course you shouldn't intend to assassinate your rival. Means-End* and Normativity cannot both be correct (cf. Bratman, Intentions, 23-30, Broome, 'Normative Requirements', 40910, 'Reasons', 29-30).

Some may be tempted to respond to these problems by suggesting that rationality is only weakly normative, in the sense that:

(Weak Normativity)

If rationality requires you to $\mathrm{A}$, there is a reason for you to A.

However, there are at least two difficulties with this move. First, many will think that there are cases in which, for example, you believe that $\mathrm{p}$ but have no reason at all not to believe not-p. If this is right, then the implications of Weak Normativity and the above requirements are still implausible. ${ }^{5}$ Second, the resulting claims - that you have some reason to avoid inconsistency in belief and means-end incoherence - do not capture the starting intuition that there is something wrong with these patterns of attitudes. For there is nothing necessarily wrong with failing to do what there is some reason to do. There is only something wrong with failing to do what there is most reason to do. Thus the strictness of requirements of belief consistency and means-end coherence - their status as requirements - cannot be explained in terms of their normativity, if only Weak Normativity is true. ${ }^{6}$ 
There is a common structure to these cases. On the one hand, there is a pattern of attitudes which seem intuitively incoherent. It is therefore natural to think that there is a requirement prohibiting this pattern. On the other hand, a natural formulation of this requirement turns out to have absurd implications. As the reader will be able to verify, the same structure applies to the following incoherent patterns and the corresponding rational requirements:

\section{Incoherent Patterns}

(Inconsistency in intention) You intend to A, intend to B, and believe that you cannot both $\mathrm{A}$ and $\mathrm{B}$.

(Modus ponens incoherence) You believe that $\mathrm{p}$, believe that if $\mathrm{p}$ then $\mathrm{q}$, and do not believe that q, although it matters to you whether q.

(Akrasia) You believe that you should A, but do not intend to A.

Rational Requirements

(Intention Consistency*) If you intend to A, and believe that you cannot both $\mathrm{A}$ and $\mathrm{B}$, rationality requires you not to intend to $\mathrm{B}$.

(Modus Ponens*) If you believe that $\mathrm{p}$, and believe that if $\mathrm{p}$ then $\mathrm{q}$, and it matters to you whether q, rationality requires you to believe that q.

(Enkrasia*) If you believe that you should $\mathrm{A}$, rationality requires you to intend to $\mathrm{A}$.

On the assumption of Normativity, each of these requirements licenses absurd conclusions about the beliefs or intentions you should have. This is the initial problem about whether you should have coherent attitudes. Since the problem arises because the above requirements are conditionals whose consequents can be detached by modus ponens, we can call this the detaching problem.

\section{Wide-Scoping}


The detaching problem has an influential solution. According to Wide-Scopers, the problem results from confusion over the logical structure of rational requirements. Rational requirements are not conditionals whose consequent says that a certain attitude is required. Rather, they are requirements to conform to a conditional. So instead of Belief Consistency* and Means-End* we have:

(Belief Consistency) Rationality requires of you that [if you believe that $\mathrm{p}$, you do not believe that not-p].

(Means-End) Rationality requires of you that [if you intend to $\mathrm{E}$ and believe that $\mathrm{M}$ is necessary for $\mathrm{E}$, you intend to $\mathrm{M}$ ].

In these formulations, 'rationality requires' takes wide-scope over the conditionals within the brackets. What these principles require is thus that you satisfy these conditionals. In other words, what these principles require is - simply - that you avoid inconsistency in belief, and means-end incoherence. ${ }^{7}$

These formulations avoid the detaching problem. Belief Consistency and Normativity together imply that you should not both believe that $\mathrm{p}$ and believe that not-p. But there are two ways to avoid this state: by not believing that $\mathrm{p}$, and by not believing that not-p. So it does not follow that if you are belief inconsistent, you should drop the belief that not-p. You might instead (or also) drop the belief that $p$. Either of these responses would bring you to comply with Belief Consistency.

Similarly, Means-End and Normativity together imply that you should not be means-end incoherent: you should not intend to $\mathrm{E}$, believe that $\mathrm{M}$ is necessary for $\mathrm{E}$, and not intend to M. But there are several ways to avoid this state: by intending to $\mathrm{M}$, by not intending to $\mathrm{E}$, and by not believing that $\mathrm{M}$ is necessary for $\mathrm{E}$. So it does not follow that if you are means-end incoherent, you should intend to M. You might instead drop the intention to E. Or you might drop the belief that M is necessary for E. Any of these responses would bring you to comply with Means-End.

The reader will be able to verify that a parallel solution is available for the other rational requirements listed above. Wide-Scoping thus offers a simple, elegant and unified treatment of the detaching problem, which allows us to maintain that we should avoid the incoherent patterns. However, in recent years it has come under severe pressure. In the next section, I outline three important objections. 


\section{Problems for Wide-Scoping}

\subsection{Does Wide-Scoping solve the Detaching Problem?}

Wide-Scoping solves the detaching problem only if all rational requirements are Wide-Scope, and there is no other way of detaching implausible conclusions from Wide-Scope requirements. Wide-Scopers have been challenged on both these fronts.

\subsubsection{The Symmetry Problem}

Wide-Scope requirements posit a kind of symmetry between the different ways of avoiding incoherence. For instance, as far as Belief Consistency goes, dropping the belief that $p$ and dropping the belief that not-p are equally good ways of escaping belief inconsistency. In this case, the symmetry seems unobjectionable. But as Niko Kolodny ('Why be Rational?') and Mark Schroeder ('The Scope', 'Means-End Coherence') point out, in other cases, the symmetry is more worrying. For instance, consider akrasia and the corresponding Wide-Scope requirement:

(Enkrasia) Rationality requires of you that [if you believe that you should A, you intend to $\mathrm{A}]$.

So far as this requirement goes, both forming the intention to A and dropping the belief that you ought to A are equally good ways of escaping akrasia. But these responses do not seem to be on a par. While it seems rational to respond to akrasia by forming the intention to $\mathrm{A}$, it does not seem rational to respond by dropping the belief that you should A.

We get similar problems for several other Wide-Scope requirements. For instance, dropping the belief that $\mathrm{M}$ is a necessary means to $\mathrm{E}$ does not seem like a good way to respond to means-end incoherence. And becoming indifferent about whether q does not seem like a good way to respond to modus ponens incoherence (cf. Schroeder 'The Scope'). What these observations suggest is that while WideScope requirements may rule out the incoherent patterns, they are not good guides to escaping incoherence. Schroeder and Kolodny both take this to show that we need at 
least some requirements directing us to form or drop particular attitudes. However, accepting such requirements threatens to return us to the detaching problem.

In response, Wide-Scopers have tended to accept the asymmetries, and attempted to show that they do not undermine Wide-Scope requirements. A common suggestion is that the asymmetries can be explained by appealing to further principles, beyond the Wide-Scope requirements. However, a worry about this suggestion is that these further principles will either return us to the detaching problem, or leave WideScope requirements redundant. The bearing of the asymmetries on the Wide-Scope approach thus remains an open question. ${ }^{8}$

\subsubsection{Detaching Wide-Scope Requirements}

Wide-Scope requirements do not allow detachment by modus ponens. But several writers have urged that they allow us to generate implausible conclusions in other ways. The starting point here is often the attractive idea that reasons and "shoulds" transmit from ends to means. Consider, for instance, that if I should attend the conference, I have a reason to take means to doing so, such as buying a plane ticket, booking a hotel, and so forth. More generally, we might accept:

(Sufficiency) If you should A, and B is a way to A, then there is a reason for you to B.

However, as Joseph Raz ('The Myth') and Matthew Bedke ('The Iffiest Oughts') observe, this leads to trouble for some Wide-Scope requirements. For instance, Means-End tells us that you should avoid the means-end incoherent combination of intending to get the job, believing that a necessary means to this is assassinating your rival, and not intending to assassinate your rival. But a way to avoid this pattern is to intend to assassinate your rival. So by Sufficiency, there is a reason to intend to assassinate your rival. Many will find this implausible.

In response, Wide-Scopers have pointed out that Sufficiency has very similar implications all by itself. For instance, as Broome ('Have we Reason', 7) points out, Sufficiency implies that when you should avoid feeling hungry this afternoon, you have a reason to kill yourself, as this is a way to avoid feeling hungry. More generally, we might observe that Sufficiency implies that whenever you should not $A$, 
you have a reason to do each and every thing that is a way of not Aing - that is, each and every thing that is incompatible with Aing. But there will be lots of cases in which some ways of not-Aing are terrible or crazy. So it is not clear that the implications of Means-End, when combined with Sufficiency, are any worse than the implications of Sufficiency alone.

A perhaps more challenging objection arises if we accept a further transmission principle:

(Necessity) If you should A and the only way to A is to B, you should B.

As Patricia Greenspan ('Conditional Oughts'), Kieran Setiya ('Cognitivism'), and Schroeder ('Means-End Coherence') have argued, there are cases in which Necessity can be applied to wide-scope requirements. Suppose, in Setiya's example, that you intend to smoke and believe that buying cigarettes is necessary for smoking. And suppose that you are psychologically incapable of dropping these attitudes. Then the only way for you to avoid means-end incoherence is to intend to buy cigarettes. And so, by Necessity, you should intend to buy cigarettes. The detaching problem has returned.

The transmission of reasons from ends to means is a distinctively practical phenomenon. So the problems raised by Sufficiency and Necessity apply only to those requirements it is natural to take as requirements of practical reason, such as Means-End and Intention Consistency. Thus Setiya ('Cognitivism') argues that the problem posed by Necessity should lead us to a cognitivist treatment of these requirements. Cognitivists hold that these apparent practical requirements on intentions are better thought of as theoretical requirements on the beliefs which correspond to, or perhaps even constitute, intentions. ${ }^{9}$ To see how this works, suppose that intending to A entails believing that you will A. Then, if you have inconsistent intentions, you will also have inconsistent beliefs. Similarly, if you are means-end incoherent, you will typically have incoherent beliefs - you will believe that you will $\mathrm{E}$, believe that you will $\mathrm{E}$ only if you $\mathrm{M}$, but not believe that you will $\mathrm{M}$. The cognitivist thought is that the theoretical requirements to avoid inconsistency and incoherence in belief thus explain what is wrong with inconsistency in intention and means-end incoherence. There is no need to accept the further practical requirements 
Means-End and Intention Consistency. Hence Necessity - which concerns the practical 'should' - gets no grip.

This cognitivist treatment faces its own difficulties. To take a problem cognitivism wears on its sleeve, it remains highly controversial whether intending entails belief. As Bratman (Intentions, 37) observes, it seems that I might intend to stop at the bookstore on my way home, even if I know that once I get on my bicycle I tend to go into 'auto-pilot', and thus do not believe that I will succeed in stopping at the bookstore. Furthermore, and crucially, the attitude I have here - whether or not we count it an intention - is subject to demands of means-end coherence. I would be irrational if I did not also intend the means to stopping at the bookstore (taking one route home rather than another, say). ${ }^{10}$

Wide-Scopers unconvinced by cognitivism must therefore find other ways to meet the challenge posed by Necessity. Thus Greenspan suggests that intentions cannot be psychologically unmodifiable; Bratman ('Intention, Practical Rationality') argues that we should restrict Means-End; Way ('Defending') suggests a restriction on Necessity.

\subsection{Why be Rational?}

Even if Wide-Scopers can solve the detaching problem, they face a further, perhaps more fundamental challenge. Each Wide-Scope requirement says you should do something: avoid inconsistency, akrasia, means-end incoherence, and so on. And so, as Kolodny ('Why be Rational?') and Broome ('Does Rationality') observe, they raise a simple question: why should you do these things? What reason do you have to do so? As Kolodny puts it in his title, 'why be rational?'

This simple question has proved surprisingly hard to answer. In 'Why be Rational?', Kolodny considers two main candidate answers. ${ }^{11}$ According to the first, there is instrumental reason to comply with rational requirements: doing so is a means to other things you should do. According to the second, you should comply with rational requirements because doing so is constitutive of being an agent with beliefs and intentions.

On their most straightforward reading though, each of these answers fails. It need not be true, in any particular case, that complying with rational requirements is a means to anything else you should do. For instance, you comply with Means-End, in 
the earlier example, when you intend to assassinate your opponent. You need not thereby do anything else you should do. Conversely, it is simply not true that if you violate a rational requirement, you are no longer an agent - akrasia, inconsistency and the rest are possible, after all.

These objections invite the reply that it is only the disposition to comply with rational requirements that is instrumentally valuable, or necessary for agency. Perhaps a disposition to satisfy rational requirements will lead you, over the long run, to achieve more of what you ought to achieve than you otherwise would. Or perhaps a creature that lacked this disposition would not be a creature with beliefs or intentions. But this reply faces its own problems. First, as Kolodny ('Why be Disposed') argues, it is in fact not so clear that the disposition to comply with rational requirements is either instrumentally valuable or necessary for having beliefs and intentions. Second, and in any case, the revised version of the suggestion does not answer the question at hand. We wanted to know why, as the Wide-Scope requirements claim, you should always avoid incoherence. It is no answer to this question to say that you should merely be disposed to be coherent.

It is the problem in particular that moves Broome ('Does Rationality') to agnosticism about even Weak Normativity. But we might worry, with Nadeem Hussain and Nicholas Southwood that this is an overreaction. Hussain and Southwood argue that to reject the normativity of rationality on this basis is to commit a mistake of the sort that H.A.Prichard claimed to see in standard treatments of the question 'why be moral?' Prichard argued that the philosopher's search for reasons to be moral - and in particular, for reasons that might persuade a rational egoist to change his ways - inevitably fails. But this is not, according to Prichard, because there are no reasons to be moral. Rather, it is because the reasons to be moral are internal to morality, and so not the kind of reasons the rational egoist can appreciate. Similarly, Hussain and Southwood worry that Broome and Kolodny fail to find reasons to comply with rational requirements not because there are no such reasons, but because such reasons are internal to rationality.

This point only takes us so far. First, there is a clear enough sense in which there are reasons 'internal' to morality. Morally obligatory actions are worth doing for their own sake. But we can reasonably question whether rational requirements enjoy a status of this sort. With Kolodny ('How Does Coherence', 241), we might find it 'outlandish that the kind of psychic tidiness that [a rational requirement] enjoins 
should be set alongside such final ends as pleasure, friendship and knowledge'. Second, there remains a clear sense in which we know what (at least some) reasons to be moral are: for instance, the fact that you promised your friend a postcard is a reason to send one; the fact that this is someone else's lunch is a reason not to take it. It is far less clear what the reasons to comply with rational requirements are. ${ }^{12}$ Third, the Hussain/Southwood point leaves open what we might take to be the heart of the 'why be rational?' challenge. It is surely correct that philosophers need not aim to convince a certain kind of skeptic of the truth of rational requirements. Nonetheless, we should expect to be able to give some kind of account of what is wrong with incoherence. It is natural, when doing this, to look for reasons to be coherent - that is just the standard way to explain why you go wrong in doing anything. If Kolodny and Broome are right that there are no obvious candidates to fill this role, we have lost an important way to show why the rational requirements hold. ${ }^{13}$

\section{Beyond the Wide-Scope Account of the Normativity of Rationality}

There is much more to be said about each of these objections. But let's suppose that some or other of them succeeds in showing that Wide-Scoping does not allow us to maintain that you should always avoid the incoherent patterns. Indeed, let's suppose it does not even allow us to maintain that there is always some reason to avoid these patterns. How should we react? Since the objections have a conjunctive target (Weak) Normativity plus Wide-Scope requirements - there are two options. We could deny that there are Wide-Scope rational requirements, or we could maintain that there are such requirements, and deny instead that rationality is even weakly normative.

We can clarify this choice by observing the parallel with a more familiar one concerning moral requirements. Suppose we come to think that there is not always reason to do what morality appears to require. For instance, suppose we come to think that what there is reason to do turns on what you happen to desire, so that someone who lacks the appropriate desires may have no reason not to lie, cheat or steal in the pursuit of egoistic ends. Would such actions nevertheless be morally wrong? Our answer to this question will depend on whether we accept the normativity of morality - whether we accept that, necessarily, if an action would be morally wrong, there is a reason not to perform it. If we do, we will have to conclude that lying, cheating, and stealing in the pursuit of egoistic ends are not morally wrong. But there is also the 
option of rejecting the normativity of morality, and holding that an action can be morally wrong, even if there is no reason not to perform it. ${ }^{14}$

Similarly, we are supposing that there is not always reason to avoid incoherence. Is coherence nonetheless rationally required? That depends on whether we accept Weak Normativity. If we do, we will conclude that coherence is not even rationally required. But there is also the option of rejecting Weak Normativity, and holding that coherence is rationally required, even if there is not always reason to be coherent. In the rest of this article, I will outline some of the challenges facing each of these responses.

\subsection{Rationality without Reasons}

The central challenge facing the latter option - maintaining Wide-Scope rational requirements while denying Weak Normativity - is simple: it needs to be said what it is for you to be rationally required to do something there is no reason to do. For recall that the notion of a rational requirement was introduced somewhat stipulatively, as a way of expressing the thought that there are norms prohibiting incoherence. But we might equally have expressed this thought by saying that you should, or have conclusive reason to, be coherent. It is therefore unclear how there could be a genuine requirement to be coherent, in the absence of reasons to be coherent. It is unclear how there can be rationality without reasons.

It is important to see that there are familiar ways of making sense of this contrast that are not easily available. For example, many philosophers accept some version of the idea that we need to distinguish between normative relations which turn on the facts of an agent's situation, and normative relations which turn on an agent's beliefs about her situation. For example, Derek Parfit claims that '[w]hile reasons are provided by the facts,... rationality...depends instead on our beliefs' (17). He illustrates this claim with the following examples:

if I believe falsely that my hotel is on fire, it may be rational for me to jump into the canal. But I have no reason to jump. I merely think I do. And, if some dangerous treatment would save your life, but you don't know that fact, it would be irrational for you to take this treatment, but that is what you have most reason to do. (17) 
As these examples illustrate, Parfit accepts that reasons and rationality can come apart. Nonetheless, there is, on Parfit's view, an explanatory connection between them. Very roughly, you are rationally required to A if you have some beliefs whose truths would give you conclusive reason to A. Parfit takes this to be a consequence of a general account on which to be rational is to respond to reasons or apparent reasons - things you believe which, if true, would be reasons. ${ }^{15}$

However, this way of distinguishing between reasons and rationality is not easily available to those who accept Wide-Scope rational requirements. Wide-scope rational requirements are not conditional on any particular beliefs. So a framework of this kind will support Wide-Scope rational requirements only if whatever you believe, you have some beliefs whose truth would give you conclusive reason to comply with Wide-Scope rational requirements. But if we are impressed by the 'why be rational?' challenge, we will be skeptical that this condition holds.

Broome ('Requirements') offers a different way of making sense of rationality without reasons. Broome points out that there are many contexts in which we speak of requirements without a commitment to the normativity of these requirements. For instance, we might agree that the law requires you to pay taxes, while questioning whether there is any reason to pay taxes. And we might grant that Catholicism requires you not to eat meat on Fridays, while denying that there is any reason not to eat meat on Fridays.

Examples of this sort suggest to Broome the following picture. There are a variety of sources of requirements. For instance, convention requires you to shake hands with your right hand, freemasonry requires you to roll up one trouser leg, morality requires you to keep promises, prudence requires you to eat healthily, the evidence requires you to believe that it rains a lot in Scotland. Some of these sources, such as morality, prudence, and the evidence, are plausibly normative - when one of these sources requires you to $\mathrm{A}$, it follows that there is a reason for you to A. Other sources - the law, convention, and freemasonry - are not normative in this way. According to Broome, rationality is simply a further source of requirements, one whose normativity is an open question.

It is not possible to assess Broome's picture in detail here. But I will register a quick worry. On the one hand, we might doubt that the clearly non-normative requirements, like those of the law, convention, and freemasonry, provide a good model for understanding rational requirements. To highlight a couple of differences, 
the requirements of the law, convention, and freemasonry are contingent and empirical, while rational requirements are plausibly necessary and a priori, if true at all. This at least suggests that any explanation of rational requirements will have to be very different from the explanation of requirements of this sort. On the other hand, the plausibly normative requirements, such as those of morality, prudence and the evidence, do seem closer to rational requirements. However, we might be more skeptical that these requirements can be understood independently of reasons. We might think that these requirements are normative not only in that they entail reasons, but in that they should be explained in terms of reasons. We might want to say, for instance, that for you to be morally required to $\mathrm{A}$ is just for the weight of moral reasons to favour Aing (cf. Darwall, Smith). But if something along these lines is right, normative requirements will not provide a model for understanding rationality without reasons either.

\subsection{Rejecting Wide-Scope Rational Requirements}

The central challenge facing the first option - that of denying that there are WideScope rational requirements - is to explain away the appeal of such requirements: intuitions to the effect that something is amiss with the various incoherent patterns.

There are several options here. Raz ('The Myth') suggests that we mistake an evaluative claim - that incoherent agents are not functioning properly - for a normative one - that we should not be incoherent. Schroeder ('The Scope', 'MeansEnd Coherence') and Way ('Defending') attempt to explain what's wrong with incoherence within a framework of the sort offered by Parfit. But the task is taken up most fully by Kolodny ('How Does Coherence', 'Why be Disposed', 'The Myth'). In what follows, I outline his approach and note two worries that arise for it.

In outline, Kolodny's approach is simple. He agrees that something is wrong if you are incoherent. But what is wrong is not that you are incoherent - the fault is not with the pattern of attitudes. Rather, incoherence guarantees that something is wrong more locally - for instance, that you believe something without sufficient evidence, or that you intend to do something you should not. That is what explains the appeal of rational requirements. 
To see how this works, consider a case of inconsistency in belief: believing $\mathrm{p}$ and believing not-p. If we are attracted to the evidentialist idea that reasons to believe are a function of the evidence, we will find it plausible that:

(Stronger Evidence) There is sufficient reason to believe that $\mathrm{p}$ only if the evidence indicates that $\mathrm{p}$ more strongly than it indicates that not-p (Kolodny 'How Does Coherence', 233).

Since the evidence cannot both indicate $\mathrm{p}$ more strongly than not-p and vice-versa, Stronger Evidence implies that you cannot have sufficient reason to believe that $p$ and sufficient reason to believe that not-p. This means that something is wrong if you believe that $\mathrm{p}$ and believe that not-p - you believe something without sufficient reason. Since this is a problem you might have if you had only one of the beliefs, the problem is not with the inconsistency as such. The inconsistency only serves to ensure that there is such a problem.

Kolodny's task is to show that something similar holds for each incoherent pattern. This turns out to be a challenging task, which I cannot discuss in detail here. But we can give a flavour of some of the difficulties by considering one of the more challenging cases, that of inconsistency in intention.

It is fairly clear that inconsistency in intention need not involve any particular attitude that you ought to give up. Thus suppose that you intend to finish your grading tonight and also intend to watch a movie, while believing that you cannot do both. While something seems wrong with this combination, it could easily be that both finishing your grading and watching a movie are perfectly choiceworthy, and that your belief cannot be faulted. In such a case, what is wrong really does seem to be the way your attitudes are combined.

However, there are ways of accommodating this point that fall short of accepting a fully Wide-Scope requirement of intention consistency. It might be, as Kolodny ('The Myth') suggests, that if you have sufficient evidence that you cannot both A and $\mathrm{B}$, then you should not both intend to $\mathrm{A}$ and intend to $\mathrm{B}$. If this is correct, then if your intentions are inconsistent, you will either have a belief you should not have, or a pair of intentions you should not have together. Kolodny seeks to defend this claim by appeal to general principles about reasons to intend, and the connections between reasons and evidence. 
Even if Kolodny's defence of this suggestion succeeds, however, there is a further worry. Suppose that you lack sufficient evidence that you cannot both finish your grading and watch a movie - you believe this only because of undue pessimism. We might nonetheless want to say that if you also have both intentions you go wrong in a further way - your ill-founded belief does not exhaust what is wrong with your state of mind. But on Kolodny's account, all that is wrong is that you believe something for which you lack sufficient evidence. So Kolodny's approach may not be able to capture all that we want to say about what is wrong with incoherence. ${ }^{16}$

\section{Works Cited}

Bedke, M. 'The Iffiest Oughts'. Ethics 119 (2009): 672-698.

Bratman, M. 'Intention, Belief, and Instrumental Rationality'. Reasons for Action. Ed.

D. Sobel and S. Wall. Cambridge: Cambridge University Press, 2009: 13-36

---. 'Intention, Belief, Theoretical, Practical'. Spheres of Reason. Ed. S. Robertson.

Oxford: Oxford University Press, 2009. 29-61.

---. Intentions, Plans and Practical Reason. Cambridge, Mass: Harvard University Press, 1987.

---. 'Intention, Practical Rationality, and Self-Governance'. Ethics 119 (2009): 411 43.

Broome, J. 'Does Rationality Give Us Reasons?' Philosophical Issues 15 (2005): 321-37.

---. 'Have We Reason to do as Rationality Requires? A Comment on Raz'. Journal of Ethics and Social Philosophy 1 (2005). http://www.jesp.org

---. 'Normative Requirements'. Ratio 12 (1999): 398-419.

---. 'Practical Reasoning'. Reason and Nature: New Essays in the Theory of

Rationality. Ed. J. Bermudez and A. Millar. Oxford: Oxford University Press, 2000. 85-112.

---. 'Reasons'. Reason and Value: Themes from the Moral Philosophy of Joseph Raz. Ed. R. J. Wallace, M. Smith, S. Scheffler and P. Pettit, P. Oxford: Oxford University Press, 2004. 28-55.

---. 'Requirements'. Homage à Wlodek: Philosophical Papers Dedicated to Wlodek

Rabinowicz. Eds. T. Rønnow-Rasmussen, B. Petersson, J. Josefsson and D. Egonsson 
(eds), Homage à Wlodek: Philosophical Papers Dedicated to Wlodek Rabinowicz. http://www.fil.lu.se/hommageawlodek

---. 'Wide-Scope or Narrow-Scope?' Mind 116 (2007): 359-70.

Brunero, J. 'The Scope of Rational Requirements'. Philosophical Quarterly 60 (2009): 28-49.

Dancy, J. Practical Reality. Oxford: Oxford University Press, 2000.

Darwall, S. Impartial Reason. Ithaca: Cornell University Press, 1983.

Foot, P. 'Morality as a System of Hypothetical Imperatives'. Philosophical Review 81 (1975): 305-15.

Gensler, H. 'Ethical Consistency Principles'. Philosophical Quarterly 35 (1985): 15670.

Greenspan, P. 'Conditional Oughts and Hypothetical Imperatives'. Journal of Philosophy 72 (1975): 259-76.

Harman, G. 'Moral Relativism Defended'. Philosophical Review 84 (1975): 3-22.

Hill, T. Jr. 'The Hypothetical Imperative'. Philosophical Review 82 (1973), 429-50.

Holton, R. Willing, Wanting, Waiting. Oxford: Oxford University Press, 2009.

Hussain, N. 'The Requirements of Rationality'. Unpublished manuscript, 2007.

Kolodny, N. 'How Does Coherence Matter?' Proceedings of the Aristotelian Society, 107 (2007), 229-263.

---. 'State or Process Requirements? Mind 116 (2007): 371-85.

---. 'The Myth of Practical Consistency'. European Journal of Philosophy 16 (3): 366-402.

---. 'Why be Disposed to be Coherent?' Ethics 118 (2008): 437-63.

---. 'Why Be Rational? Mind 114 (2005): 509-63.

Mackie, J. Ethics: Inventing Right and Wrong. New York: Penguin, 1977.

Parfit, D. 'Rationality and Reasons'. Exploring Practical Philosophy: From Action to Values. Eds. D. Egonsson, B. Petersson, J. Joselfsson, and T. Rønnow-Rasmussen, T. Aldershot: Ashgate, 2001: 17-39.

Prichard, H.A. 'Does Moral Philosophy Rest on a Mistake?' Mind 21 (1912), 21-37.

Raz, J. 'The Myth of Instrumental Rationality'. Journal of Ethics and Social Philosophy 1 (2005), 2-28. http://www.jesp.org.

Ross, J. 'How to be a Cognitivist about Practical Reason'. Oxford Studies in Metaethics, Volume 4. Ed. Shafer-Landau, R. Oxford: Oxford University Press, 2009. 243-282. 
Schroeder, M. 'Having Reasons'. Philosophical Studies 139 (2008): 57-71.

---. 'Means-End Coherence, Stringency, and Subjective Reasons'. Philosophical

Studies 43 (2009): 223-248.

---. Slaves of the Passions. Oxford: Oxford University Press, 2007.

---. 'The Scope of Instrumental Reason'. Philosophical Perspectives 18 (2004): 337-

64.

Setiya, K. 'Cognitivism About Instrumental Reason'. Ethics 117 (2007): 649-73.

Smith, M. The Moral Problem. Oxford: Blackwell Publishing, 1994.

Southwood, N. 'Vindicating the Normativity of Rationality'. Ethics 119 (2008): 1-30.

Velleman, D. 'What Good is a Will?' Action in Context. Eds. A. Leist and H.

Baumann. New York: Mouton, 2007. 193-215.

Wallace, R. J. 'Normativity, Commitment and Instrumental Reason' Philosophers'

Imprint 1 (2001).

Way, J. 'Defending the Wide-Scope Approach to Instrumental Reason'.

Philosophical Studies. 147 (2010): 213-33.

(forthcoming). The Symmetry of Rational Requirements. Philosophical

Studies.

\footnotetext{
${ }^{1}$ Here and throughout I use 'should' as an overall, or "all-things-considered" notion - if you should A, that settles the question of whether to A. 'Reasons' are pro tanto (or "contributory") normative reasons - considerations which count for or against actions and attitudes, and which together determine what you should do.

2 The use of 'rational requirement' for this sort of requirement may suggest the thesis that rationality requires only coherence (cf. Smith, Broome, 'Does Rationality'). However, the issues to be discussed about this sort of rational requirement are largely independent of the question of whether these are the only rational requirements.

${ }^{3}$ Compare Broome, 'Normative Requirements', 405-6 on the requirement to believe the consequences of your beliefs.

${ }^{4}$ Strictly speaking, something is going wrong only if you also believe that intending to $\mathrm{M}$ is necessary for Ming (cf. Harman, 52-60, Broome 'Practical Reasoning', 90-92, Setiya, 667-9). For simplicity, I will ignore this complication.

${ }^{5}$ However, see Schroeder, Slaves, 92-7 for discussion of whether implications of this sort are really implausible.

${ }^{6}$ For emphasis on this point, see Bratman, Intentions 24, Broome 'Normative Requirements', Setiya, 653-4, Schroeder 'Means-End Coherence', Way 'Defending'.

${ }^{7}$ The Wide-Scope view is presented with particular clarity and force by John Broome ('Normative Requirements', 'Reasons', 'Does Rationality'). See also Hill, Greenspan, Darwall, Gensler, Dancy, Wallace, Setiya, Way ('Defending', 'The Symmetry').

${ }^{8}$ For discussion see Broome 'Wide-Scope', Brunero, Hussain, Kolodny 'State or Process

Requirements?', Way 'The Symmetry'.

${ }^{9}$ For this idea see Harman, Wallace.

${ }^{10}$ For discussion of cognitivism see Bratman ('Intention, Belief, Practical, Theoretical', 'Intention, Belief, and Instrumental Rationality'), Holton, Ross, Velleman.

${ }^{11}$ Compare also Broome, 'Does Rationality', Kolodny, 'How Does Coherence', 'Why be Disposed', Southwood, and Way 'Defending'.
} 


\footnotetext{
${ }^{12}$ Hussain suggests that a reason to be coherent is simply that coherence is rationally required. But we might worry that this is like saying that a reason not to steal is that stealing is morally wrong. While it may be true, its truth requires that there are further underlying reasons that explain why it is wrong. In the case of rationality, we do not know what these reasons are.

${ }^{13}$ To an extent, both Hussain and Southwood acknowledge the explanatory demand here. Southwood says that we need an account of the "normativity" of rational requirements, while Hussain emphasizes the need for a "meta-ethics" of rational requirements.

${ }^{14}$ See Harman and Mackie for examples of the first of these options, and Foot for an example of the second.

${ }^{15}$ Many other authors make similar suggestions in slightly different terms. For instance, many authors distinguish, along these lines, between objective and subjective senses of 'ought' and 'reason'. For discussion, see Schroeder 'Having Reasons'.

${ }^{16}$ Thanks to Errol Lord, Josh May, and Mark Schroeder, for very helpful comments.
} 